\title{
Stereotactic Radiosurgery for the Treatment of Brain Metastases from Non- Small Cell Lung Carcinoma: A Multi- institutional Experience
}

Aizik L. Wolf ${ }^{1}$, Sachin Batra ${ }^{2}$, Pietro Bortoletto ${ }^{3}$, Chetan Bettegowda $^{2}$, Beatriz E. Amendola 4 , Laurie Blach ${ }^{5}$, Lawrence Kleinberg ${ }^{6}$, Daniele Rigamonti ${ }^{7}$

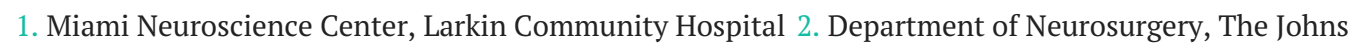
Hopkins University School of Medicine, Baltimore Maryland 3. Feinberg School of Medicine 4. Innovative Cancer Institute 5. Miami Neuroscience Center, Mount Sinai Medical Center, Miami Beach, Florida 6. Department of Radiation Oncology, Johns Hopkins University School of Medicine 7. Department of Neurosurgery, The Johns Hopkins University School of Medicine

$\square$ Corresponding author: Aizik L. Wolf, awolf@larkinhospital.com Disclosures can be found in Additional Information at the end of the article

\section{Abstract}

Background: Non-small cell lung carcinoma (NSCLC) is one of the most common types of cancer metastatic to brain. Several series report radiosurgery to have a median survival of six to 12 months after NSCLC brain metastasis. We report our experience and describe predictors of survival in NSCLC. In our study, one of the largest multicenter series of patients with NSCLC, we describe survival after stereotactic radiosurgery (SRS) and prognostic markers in patients with KPS $\leqslant 70 /$ RPA III in contrast to patients with higher KPS.

Methods: Patient records of 468 patients with complete data at Miami Neuroscience Center and Johns Hopkins Hospital were retrospectively reviewed for predictors of survival. The KaplanMeier survival analysis and log-rank test were performed to calculate and compare median survival from radiosurgery. Survival was compared between pre-radiosurgery Karnofsky performance status (KPS) $>70$ versus $\leqslant 70$ using log-rank test. Further analysis using multivariate Cox regression identified predictors of survival in patients with KPS $\leqslant 70$.

Results: Four hundred and seventeen (89.1\%) patients died over a mean follow-up duration of 11.98-19.21 months with an overall median survival time of 7.14 months since treatment. Median survival differed by KPS (KPS $\leqslant 70: 4.34$ months; KPS $>70: 7.89$ months; $(p=0.0003)$ ). Overall factors associated with mortality included KPS score of 70 (hazard ratio 1.54, $\mathrm{P}<0.001$ ), age above 65 years (hazard ratio 1.43, $\mathrm{P}<0.001$ ), presence of more than three lesions (hazard ratio $1.51, \mathrm{p}<0.0001$ ), dose of or less than 18Gy (hazard ratio: $1.4, \mathrm{p}=.005$ ). Amongst patients with KPS $\leqslant 70$, none of the above factors were found to predict mortality, except with the diagnoses of brain metastases at the time of diagnoses of cancer (synchronicity) (Odds ratio 1.89). Patients with synchronous lesions had a median survival of 2.5 months while patients with metachronous lesions had a median survival rate of 6.09 months $(p=0.0062)$. No significant difference was observed between survival of patients with KPS >70 (mortality: 87.7\%, median survival: 7.89 months) and patients with metachronous lesions in KPS $\leqslant 70$ subgroup (Mortality: 91.3\% \& median survival: 6.09 months) $p=0.38$.

Conclusions: Local control of radiosurgery and predictors of survival for patients with poor KPS differ from patients with good performance status. Patients with KPS $\leqslant 70$ and metachronous lesions may be candidates for aggressive treatment in patients with KPS $>70$. 
Categories: Radiation Oncology, Neurosurgery

Keywords: Stereotactic Radiosurgery, Outcomes, progression, mortality, non-small cell lung carcinoma

\section{Introduction}

Non-small cell lung carcinoma (NSCLC) is one of the most common types of cancer that metastasize to the brain. Autopsy studies have revealed $8-41 \%$ prevalence of brain metastasis in patients with bronchogenic carcinoma [1]. When treated conservatively with steroids and medical management, the survival for brain metastasis is one to two months, independent of histology [2]. Several studies have demonstrated that radiosurgery enhances the survival to six to 12 months in patients with NSCLC [3-5]. This efficacy, however, may not be observed in a subclass of patients with poor functional/performance status, often described as Karnofsky performance scores (KPS) $\leqslant 70$. KPS is one of the most consistently observed predictors of poor survival and is a component of recursive partition analysis (RPA) classification, a most widely used parameter to select patients for aggressive treatment. The role of other factors, such as number of lesions, location of lesions, volume, and gender as prognostic factors, is not clear [2, 6-8]. Other factors like delay in onset of metastatic disease are not considered in RPA classification during the selection of patients for radiosurgical or surgical treatment [2, 4, 6-9]. Furthermore, selection bias towards the aggressive management of patients with accepted favorable prognostic factors prevents evaluation of subgroups with poor prognosis [10]. So far, only a few series have analyzed predictors of survival in patients with poor KPS [9, 11-12].

\section{Materials And Methods}

\section{Patients and methods}

Prior to initiation, approval was gained from the Johns Hopkins Institutional Review Board to perform this study. We retrospectively reviewed data collected from chart review of 482 patients who received stereotactic radiosurgery to treat metastatic brain lesions from NSCLC. Fourteen patients did not return for follow-up after SRS and were excluded, yielding 468 patients that were eligible for analysis. Amongst these patients, 383 patients were treated at Miami Neuroscience Center, Miami, FL (MNC) from 1993 to 2009, while 85 patients were treated at Johns Hopkins Hospital, Baltimore, MD (JHH) between 2003 and 2007. The histopathological diagnosis was confirmed by a biopsy of the primary tumor or of a metastatic lesion at an extracranial site or from tissue obtained during craniotomy. Patients were evaluated for neurologic and radiographic progression initially at four weeks post-radiosurgery and subsequently at three month intervals. Any local recurrence or new metastatic disease was treated with subsequent sessions of radiosurgery or craniotomy.

\section{Gamma Knife}

All lesions were treated using Leksel I Gamma Knife model U, model B or model C (Elekta Instruments, Stockholm, Sweden). The decision to treat with SRS was determined after consultation with a neurosurgeon and radiation oncologist at the respective centers. Patients harboring multiple lesions were sometimes treated in multiple sessions. The prescription dose was based on volume, number, and location of lesions, with deep lesions and those located in proximity to critical neurovascular lesions receiving a lower dose. The median prescription dose at MNC was $15 \mathrm{~Gy}$ (I QR: 15-18 Gy), whereas patients at JHH received a significantly higher dose with a median of 18 Gy (IQR: 16 Gy-20 Gy) (p<0.001).

\section{Statistical analysis}

The demographic and clinical features of patients included in this study are summarized in Table 1. 


\section{Cureus}

\begin{tabular}{|c|c|c|c|}
\hline & MNC & JHH & $\mathbf{p}$ \\
\hline $\mathrm{N}$ & 383 & 85 & \\
\hline \multicolumn{4}{|l|}{ Age } \\
\hline Median Age (IQR) & $62(55-70)$ & $59(52-66)$ & 0.013 \\
\hline Age $>65$ & $229(59.79 \%)$ & $63(74.12 \%)$ & 0.009 \\
\hline Age $<65$ & $154(40.21 \%)$ & $22(25.88 \%)$ & \\
\hline \multicolumn{4}{|l|}{ Gender } \\
\hline Males & $184(48.04 \%)$ & $40(47.06 \%)$ & 0.90 \\
\hline Female & $199(51.86 \%)$ & $45(52.44 \%)$ & \\
\hline \multicolumn{4}{|l|}{ Number of lesions } \\
\hline 1 lesion & 139 (36.29\%) & $36(43.37 \%)$ & 0.044 \\
\hline 2-3 lesions & $113(26.50 \%)$ & $30(36.14 \%)$ & \\
\hline >3 lesions & $131(34.20 \%)$ & $17(20.49 \%)$ & \\
\hline \multicolumn{4}{|l|}{ Lesion volume } \\
\hline$<3.7$ (p25) & $53(13.84)$ & $58(69.88)$ & $<0.001$ \\
\hline 3.7-8.4 ml (p25-p50) & $108(28.20)$ & 16 (19.28) & \\
\hline 8.4-17.59 ml (p50-p75) & 109 (28.46) & $6(7.23)$ & \\
\hline >17.59ml (> p75) & $113(29.50)$ & $3(3.61)$ & \\
\hline \multicolumn{4}{|l|}{ KPS } \\
\hline Median KPS (IQR) & $90(80-90)$ & $80(80-90)$ & 0.24 \\
\hline $\mathrm{KPS}<=70$ & $81(23.01 \%)$ & $11(18.03 \%)$ & 0.50 \\
\hline KPS>70 & $271(76.99 \%)$ & $50(81.97 \%)$ & \\
\hline \multicolumn{4}{|l|}{ Time to diagnosis of metastasis } \\
\hline$<6$ months & $220(58.98 \%)$ & $39(53.42 \%)$ & 0.43 \\
\hline$>6$ months & $153(41.02 \%)$ & $34(46.58 \%)$ & \\
\hline \multicolumn{4}{|l|}{ Treatment } \\
\hline GK & $297(84.35 \%)$ & $66(77.65 \%)$ & 0.09 \\
\hline GK+WBRT & 55 (15.63\%) & $19(22.35 \%)$ & \\
\hline Median treatment dose GK (IQR) & $16(15-18)$ & $18(16-20)$ & $<0.001$ \\
\hline
\end{tabular}




\section{Cureus}

\section{TABLE 1: Demographics and clinical features of patients}

Frequencies and percentage were obtained when data was categorical and compared using the Fisher's exact test. Similarly, measures of continuous variables were summarized as medians and interquartile ranges (IQR) and compared using Wilcoxon's Sum of Rank test. When treatment was administered in multiple sessions, the lowest dose received by lesions at all sessions was used for the analysis. The survival times were expressed as the time to death from the last radiosurgery treatment. Progression-free survival (PFS) was calculated as the time from last treatment until subsequent intracranial progression or death. The median survival times and progression-free survival were calculated using Kaplan-Meier Analysis Cumulative failure rates were derived from life table analysis (Table 2). Patients were censored at last follow-up when there was no mortality or progression during Kaplan-Meier analysis for survival and PFS, respectively. The median survival were further stratified by the clinical and demographic features, such as treatment centers (JHH and MNC), age groups (age $\leqslant 65$ years, age > 65 years), Karnofsky performance scores (KPS) (KPS > 70, $\leqslant 70$ ), number of lesions (solitary lesion, two to three lesions, $>3$ lesions), and volume (dichotomized by median volume: $<8.4 \mathrm{ml}, \geqslant 8.4 \mathrm{ml}$ ), histology (adenocarcinoma, mixed NSC, and NSCLC-not classified), and interval between diagnosis of primary NSCLC to diagnosis of intracranial metastasis ( $\leqslant 2$ months, $>2$ months). The survival times were compared between the strata and the two centers using Log Rank Test. The patients who did not die or progress during the follow-up were censored at last follow-up as required by the analysis. The Cox proportional hazard model was used to estimate relative risk of overall mortality attributable to covariates described above using univariate (Table 3) and multivariate analysis.

\begin{tabular}{|c|c|c|c|c|c|c|c|c|c|c|c|c|}
\hline \multirow[t]{2}{*}{ Strata } & \multirow[b]{2}{*}{$\mathrm{N}$} & \multicolumn{3}{|l|}{ MNC: $\mathbf{N}=\mathbf{3 8 3}$} & \multicolumn{4}{|c|}{ JHH: N=86 } & \multicolumn{4}{|c|}{ Overall: $\mathrm{N}=469$} \\
\hline & & Dead (\%) & $\begin{array}{l}\text { Median Survival } \\
\text { Time }(95 \% \mathrm{Cl})\end{array}$ & $\begin{array}{l}\text { Log-rank p- } \\
\text { value (between } \\
\text { strata) }\end{array}$ & $\mathrm{N}$ & Dead (\%) & $\begin{array}{l}\text { Median Survival } \\
\text { Time (95\% Cl) }\end{array}$ & $\begin{array}{l}\text { Log-rank p- } \\
\text { value (between } \\
\text { strata) }\end{array}$ & $\mathrm{N}$ & Dead (\%) & $\begin{array}{l}\text { Median Survival } \\
\text { Time }(95 \% \mathrm{Cl})\end{array}$ & $\begin{array}{l}\text { Log-rank p- } \\
\text { value (between } \\
\text { strata) }\end{array}$ \\
\hline Center & 383 & 360 (93.99) & $6.81(5.99-7.89)$ & & 85 & $57(67.05)$ & $\begin{array}{l}8.35(4.76- \\
12.10)\end{array}$ & & 468 & $417(89.1)$ & $\begin{array}{l}7.14(6.09- \\
7.93)\end{array}$ & 0.4 \\
\hline \multicolumn{13}{|l|}{ Age } \\
\hline Age $<65$ & 229 & $210(91.70)$ & $7.8(6.15-8.78)$ & \multirow{2}{*}{0.008} & 63 & $41(65.07)$ & $\begin{array}{l}9.07(4.34- \\
12.33)\end{array}$ & \multirow{2}{*}{0.46} & 292 & 251 (85.95) & $\begin{array}{l}7.86(6.22 \text { - } \\
9.14)\end{array}$ & \multirow{2}{*}{0.006} \\
\hline Age $>65$ & 154 & $150(97.40)$ & $6.09(4.64-7.4)$ & & 22 & 16 (72.72) & $\begin{array}{l}7.89(3.98- \\
12.13)\end{array}$ & & 176 & 166 (96.51) & $\begin{array}{l}6.25(4.64- \\
7.73)\end{array}$ & \\
\hline \multicolumn{13}{|l|}{ Gender } \\
\hline Females & 184 & 170 (92.39) & $7.2(5.82-7.93)$ & \multirow{2}{*}{0.82} & 40 & $28(70)$ & $\begin{array}{l}11.25(4.76- \\
12.4)\end{array}$ & \multirow{2}{*}{0.61} & 224 & 198 (88.39) & $7.4(6.09$ - 7.96$)$ & \multirow{2}{*}{0.73} \\
\hline Male & 199 & $190(95.47)$ & $6.55(5.36-8.78)$ & & 45 & 29 (64.44) & $\begin{array}{l}7.89(4.01- \\
11.34)\end{array}$ & & 244 & 219 (89.75) & $\begin{array}{l}6.55(5.39- \\
8.59)\end{array}$ & \\
\hline \multicolumn{13}{|c|}{ Number of lesions } \\
\hline 1 lesions & 139 & 132 (94.96) & $93(6.09-$ & & 36 & $24(66.7)$ & $8.35(4.67-$ & & 176 & 156 (89.14) & $8.35(6.09-$ & \\
\hline
\end{tabular}




\section{Cureus}

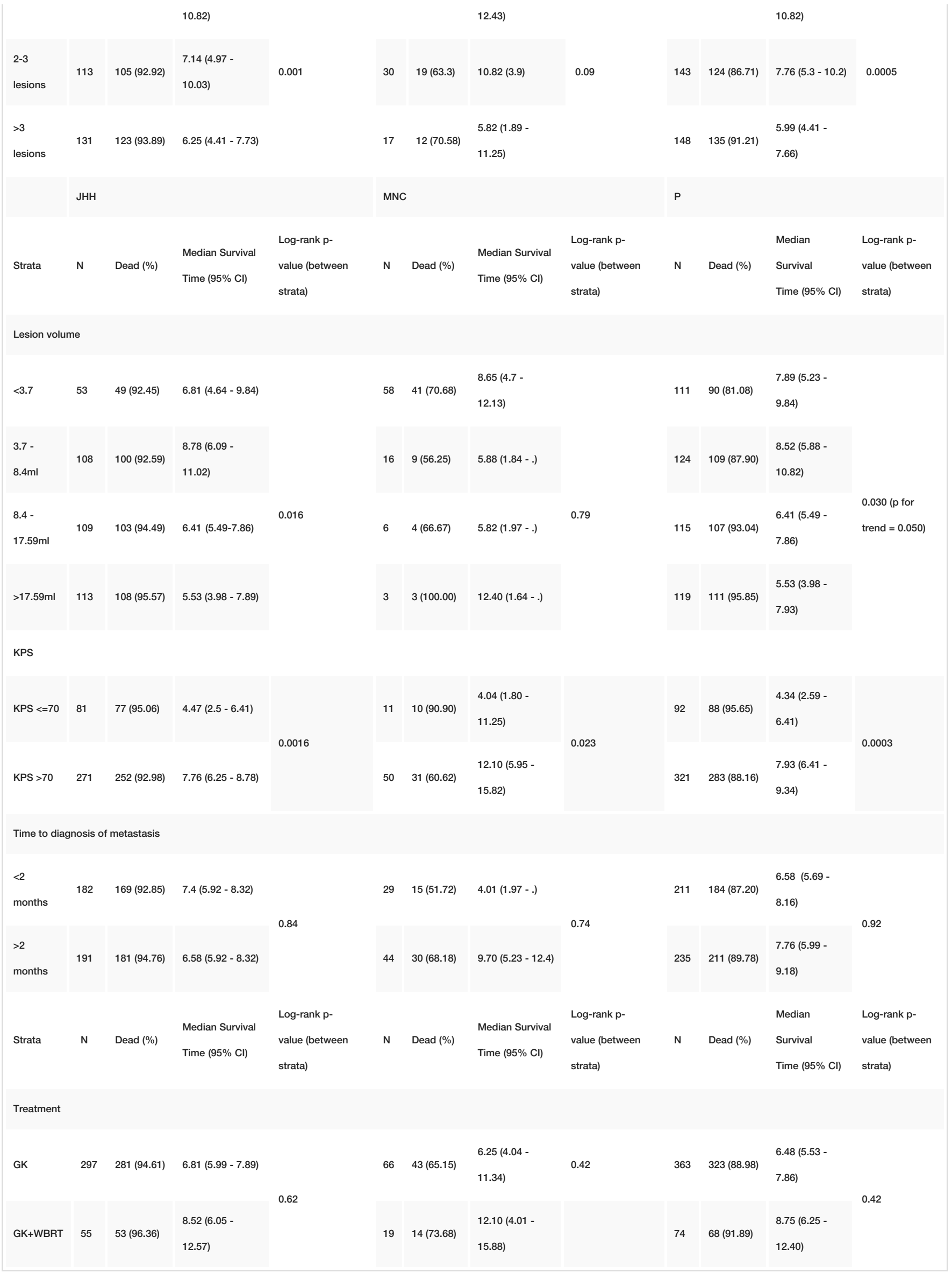

TABLE 2: Survival time and progression-free survival 


\section{Cureus}

Prognostic factor

Age $>65$

KPS $<70$

Lesions $>3$

Volume $>8.4 \mathrm{cc}$

Synchronicity of brain metastasis

Dose $<18$

Male

GK+WBRT
Odds Ratio (95\% Cl)

$1.32(1.09-1.61)$

$1.59(1.25-2.02)$

$1.49(1.21-1.84)$

$1.29(1.07-1.57)$

$1.00(0.82-1.22)$

$1.32(1.09-1.61)$

$1.03(0.85-1.25)$

$0.89(0.68-1.15)$
$\mathbf{P}$

0.005

$<0.001$

$<0.001$

0.008

0.97

0.005

0.73

0.38

\section{TABLE 3: Univariate odds ratios of prognostic factors}

The multivariate model was analyzed with patients stratified by KPS (KPS > 70 and KPS $\leqslant 70$ ). All p-values reported are two-sided. The analysis was performed using Stata version 12 (Stata Corp LP: College Station, TX) and R version 2.13.0 (2011-04-13). Cumulative incidence of brain metastases related (BMR) mortality was derived using non-brain metastases-related (non-BMR) mortality as competing risk factor and compared between covariates using Grays test. Standardized Hazard ratios (SHR) for predictors of brain metastases-related mortality were derived using competing risk regression. For the purpose of analysis, continuous variables were dichotomized using univariate CART (Classification and regression tree) analysis for censored data (cart command in STATA).

\section{Results}

During a mean follow-up time of 11.98 months (95\% CI 10.23-13.72 months), 417 (89.1\%) patients died with median survival time of 7.14 months (95\% CI: 6.09-7.93 months).

\section{Cumulative incidence of mortality caused by brain metastases and other causes}

Of the 329 patients in whom data regarding neurological mortality was available, 28 (8.5\%) patients had died from neurological mortality. Cumulative incidence of BMR and non-BMR mortality using competing risk analysis at 12 months was $6.67 \%$ (95\% $\mathrm{Cl}: 4.65-9.60 \%)$ and 61.95\% (95\% Cl: 56.54-66.88\%), respectively. While, at 36 months, cumulative incidence of BMR and non-BMR mortality was 8.25\% (95\% Cl: 5.62- 11.50\%) and 85.11\% (95\% Cl 80.74$88.56 \%$ ), respectively. Multivariate competing risk regression after adjusting for age $>65$, KPS $>70$, dose $\leqslant 16 \mathrm{~Gy}$, lesions (2-3 and > 3) revealed patients treated with dose $\leqslant 17$ Gy were 5.83 times more likely to die of BMR cause than those treated higher dose (SHR: 5.83, 95\% Cl 1.28-26.50, $\mathrm{p}=0.02$ ). None of the other variables dose was adjusted for, such as KPS > 70, 2-3 lesions, $>3$ lesions, volume $>12 \mathrm{cc}$, age $>65$ and male gender predicted brain metastases 
related mortality with standardized hazard ratios (SHR) of 0.67 (95\% $\mathrm{Cl}: 0.28-1.58, \mathrm{p}=0.36)$, 1.58 (95\% Cl: $0.53-4.69, \mathrm{p}=0.40$ ), 1.63 (95\% Cl: $0.60-4.42, \mathrm{p}=0.33), 1.97$ (0.93 - 4.20, p=0.07), 1.04 (95\% Cl: 0.42- 2.56, p=0.92) and $1.12(0.50-2.47, \mathrm{p}=0.77)$, respectively. The two centers had comparable survival times with patients at JHH and MNC surviving for a median of 8.35 months (95\% CI: 4.76-12.10 months, 67.05\% mortality) and 6.81 (5.99-7.89 months, 93.99\% mortality), respectively ( $\mathrm{p}=0.34$ ). At one year, cumulative mortality was $70.6 \%$ (95\% CI: $66.41 \%$ 74.64\%) while at 18 months $80.75 \%$ (95\% CI: 76.84\%-84.37\%) patients were not alive.

Survival was subsequently compared by various predictors of mortality. Patients who were older than 65 years had a median survival of 6.25 months (95\% CI: 4.64-7.73 months, $96.51 \%$ mortality) as compared to 7.83 months (95\% CI: 6.22-9.14 months, $85.95 \%$ mortality) in patients who were younger $(\mathrm{p}=0.004)$ (Figure 1$)$.

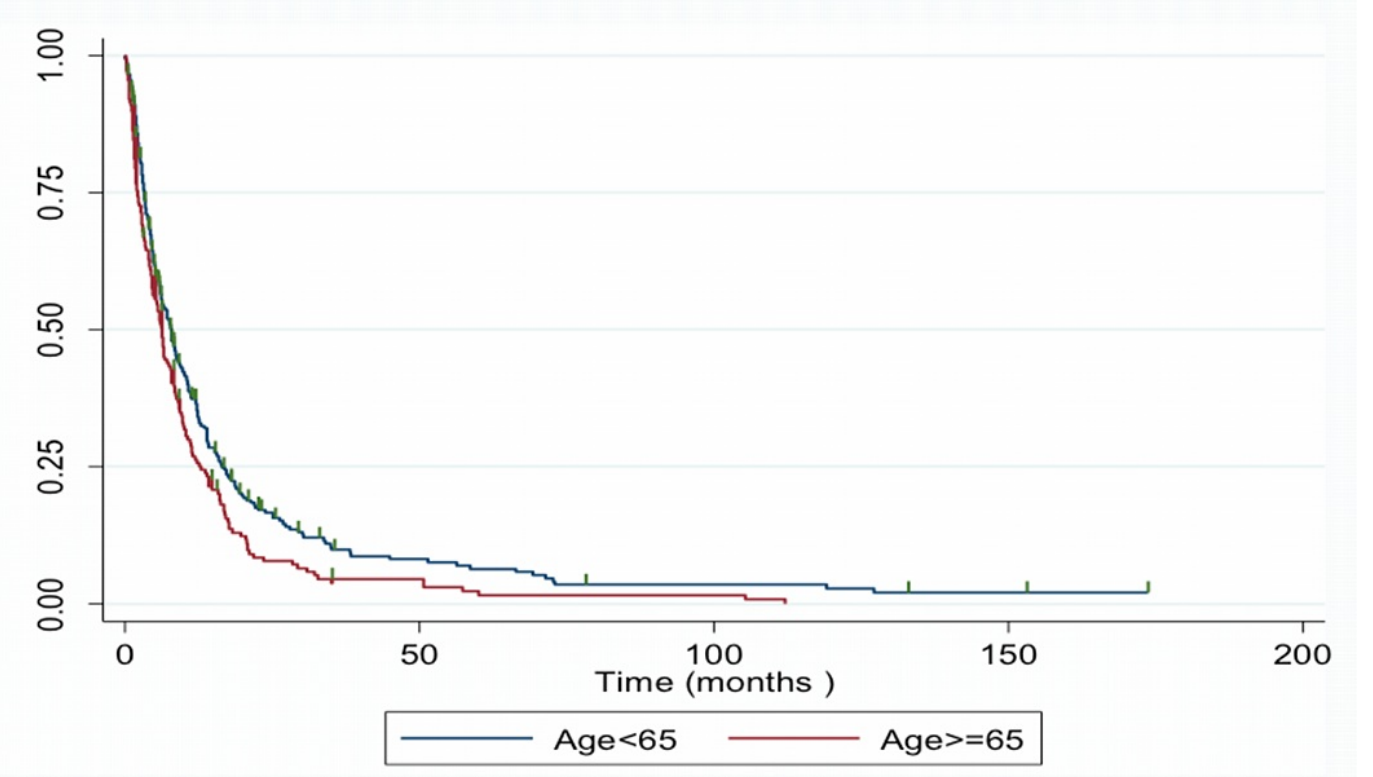

FIGURE 1: Survival by age

Survival time when compared to the number of lesions (Figure 2) revealed that solitary lesions had significantly higher overall survival time of 8.35 months (95\% CI: 6.09-10.82 months, 89.14\% mortality) when compared to patients with multiple lesions, who survived for a median of 5.99 months ( $95 \% \mathrm{Cl}: 4.41-7.66$ months, $91.21 \%$ mortality) $(\mathrm{p}=0.0005)$. When the survival of patients harboring four or more lesions was compared to those harboring three or fewer lesions, significantly higher survival was found in the latter group. The overall survival for patients with four or more lesions was six months ( $95 \% \mathrm{Cl}$ : 4.41-7.66 months, 91.2\% mortality, while in patients with three or fewer lesions the median survival was 7.86 months $(95 \% \mathrm{Cl}: 6.22-9.77$ months, $87.85 \%$ mortality). 


\section{Cureus}

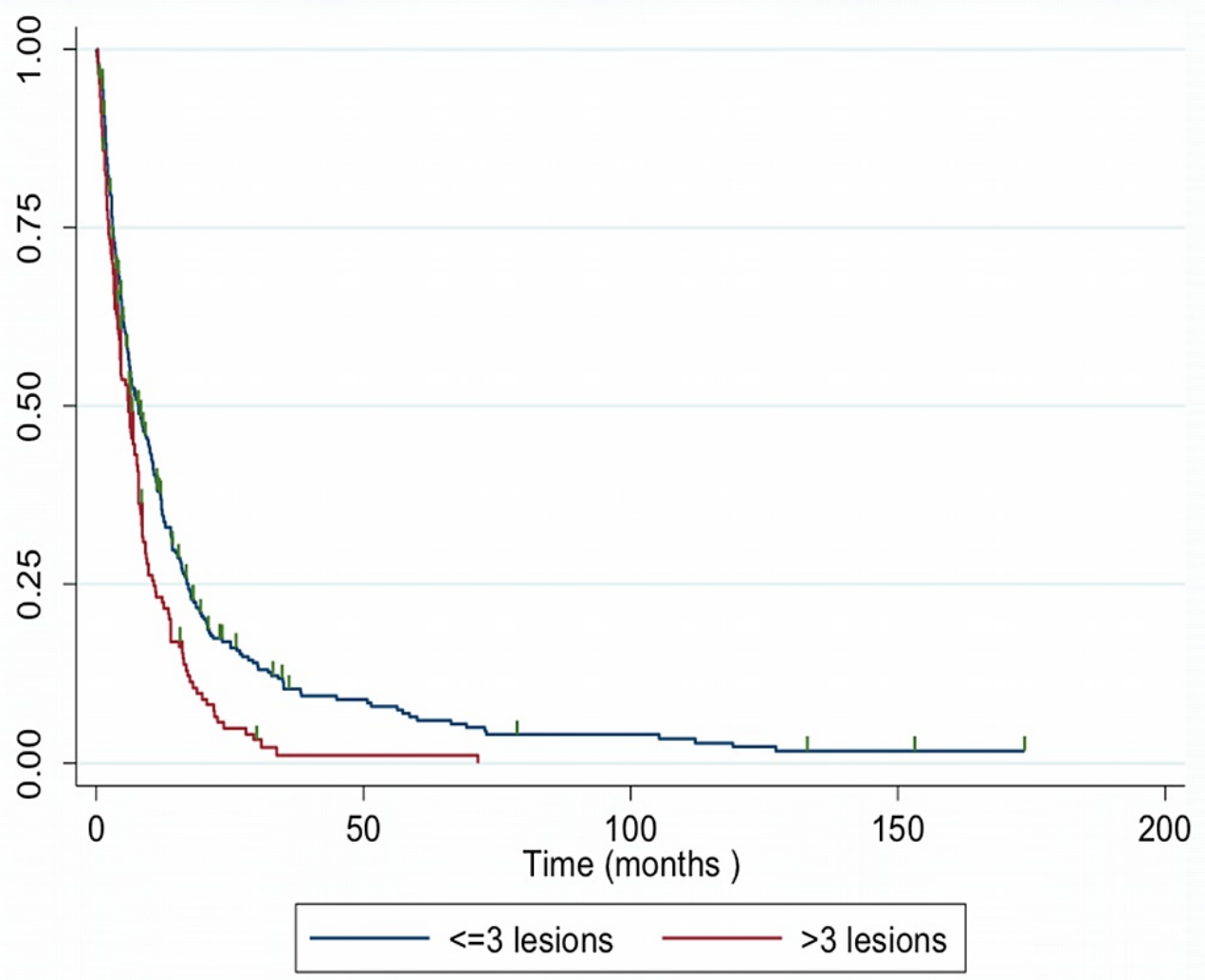

FIGURE 2: Survival by number of lesions

This difference was found to be significant across the treatment centers. One year after radiosurgery, $62.35 \%$ (95\% CI: 56.9-67.79\%) of the patients with less than four lesions were dead, whereas 76.78\% (95\% CI: 69.33-83.53\%) died amongst those with four or more lesions. Patients when categorized by Karnofsky Performance Scores (KPS) (Figure 3) showed a significantly higher survival time with KPS >70 (median survival 7.89 months, 95\% CI: 6.41-9.51 months) when compared to patients with a KPS $\leqslant 70$ (median survival 4.34 months, $95 \% \mathrm{CI}$ 2.59-6.41 months). 


\section{Cureus}

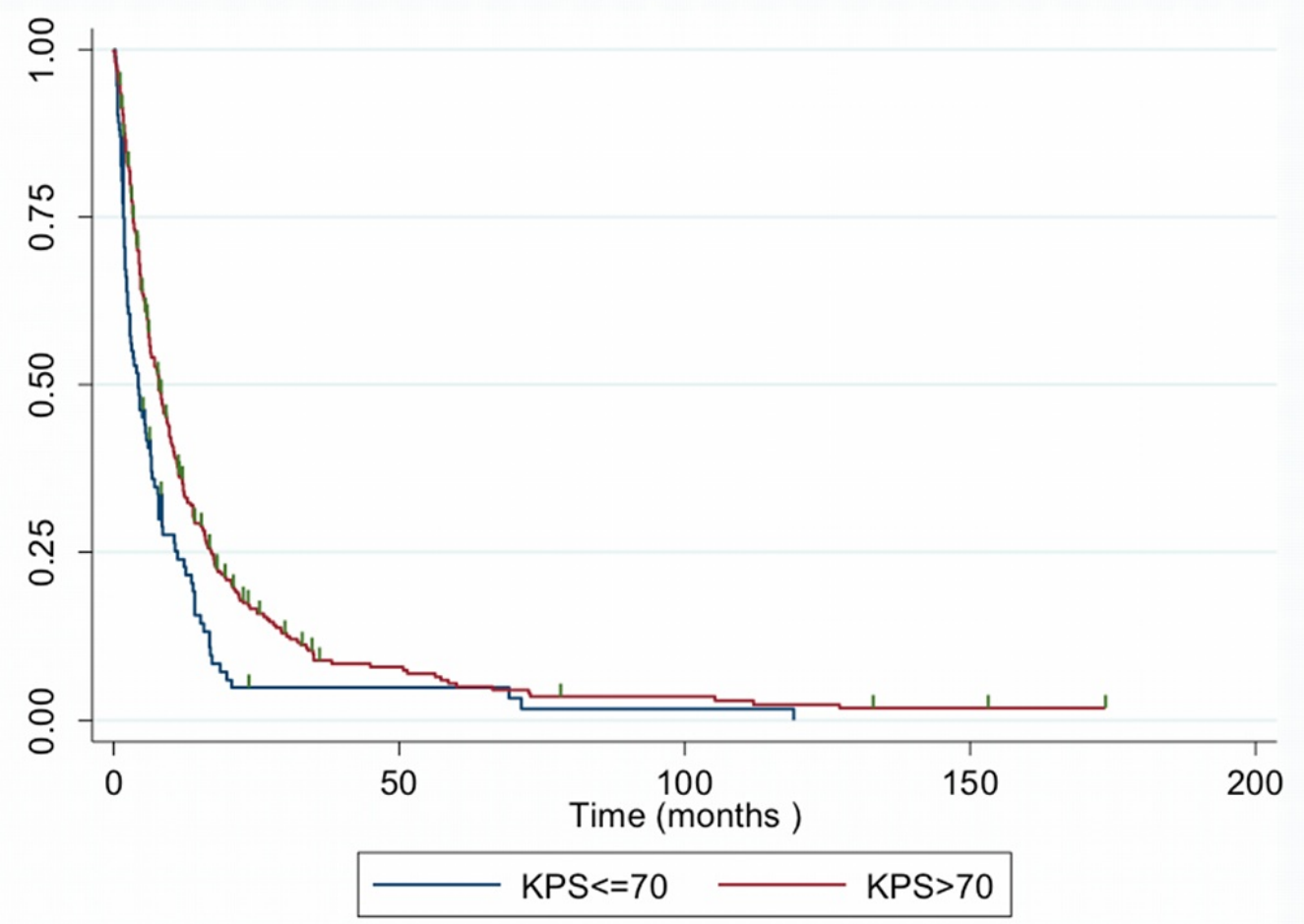

FIGURE 3: Survival by KPS

Patients with cumulative median lesion volume of less than $(8.4 \mathrm{cc}$ ) (Figure 4 ) had a median survival of 8.36 months (95\% CI: 6.09-9.84 months), as compared to 6.28 months (95\% CI: 4.77.73 months) in those harboring tumor volumes greater than $8.4 \mathrm{cc}(\mathrm{p}=0.007)$. There was no difference in median survival when comparing gender and histological subtypes of NSCLC. Males had a median survival time of 7.4 months ( $95 \%$ CI 6.09- 7.96 months) while females survived for a median duration of 6.55 months ( $95 \%$ CI 5.39-8.59 months) $(\mathrm{p}=0.73)$. Amongst histological subgroups, NSCLC-not classified was the largest group of 253 patients (53.94\%) followed by adenocarcinoma with 158 (33.69\%) and the remaining 58 (12.37\%) patients were classified as "others" due to relatively few patients in each of the other histological classes. Patients harboring adenocarcinoma had a median survival of 6.61 months $(95 \% \mathrm{Cl}$ : 5.99-8.42 months), while "NSCLC-not classified" and "other" histologies survived for 7.8 months and 5.3 months, respectively $(\mathrm{p}=0.66)$. Similarly, no differences in survival were found in patients who developed brain metastasis within six months of diagnosis of NSCLC versus those with delayed development of brain metastasis $(\mathrm{p}=0.95)$. 


\section{Cureus}

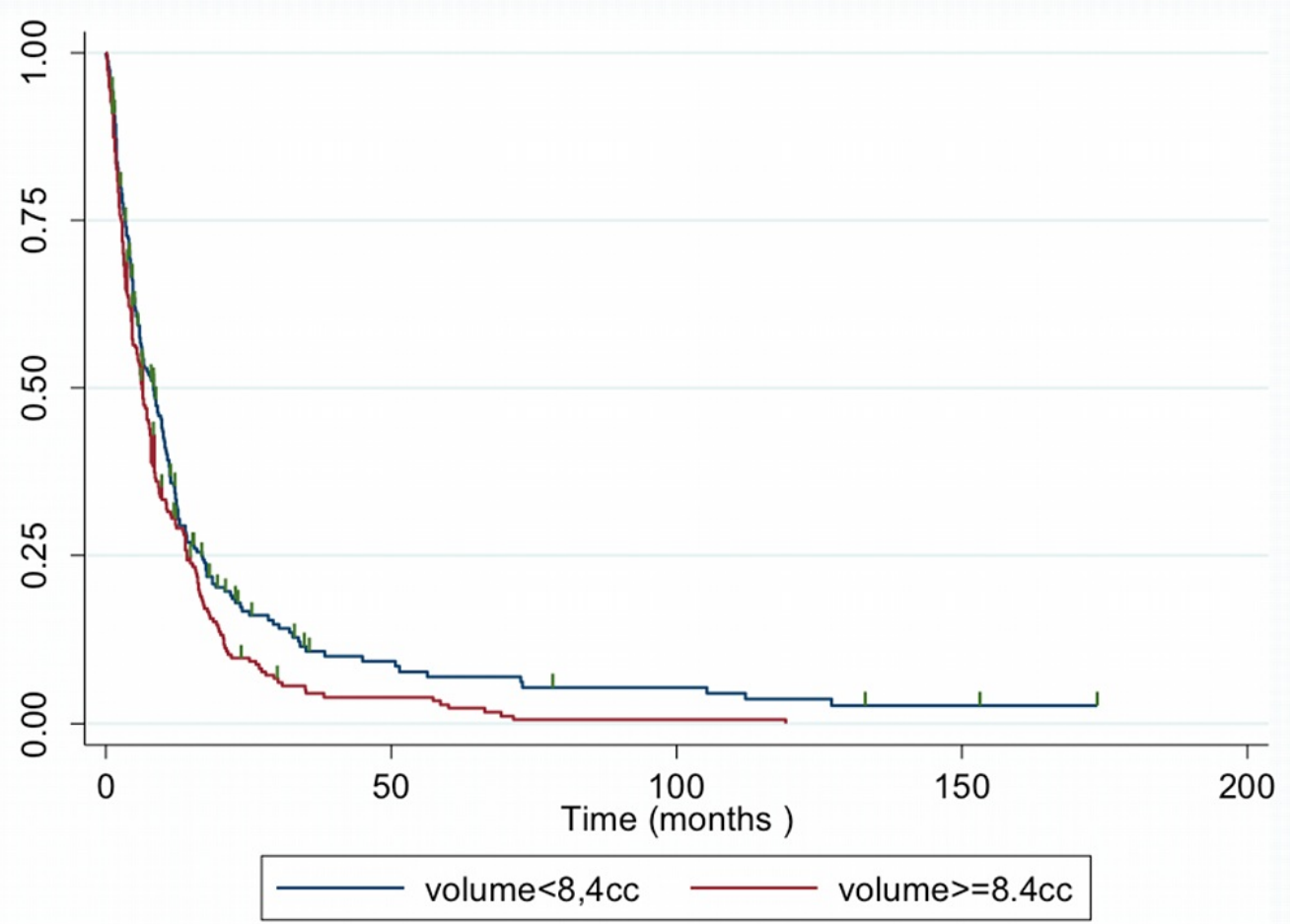

FIGURE 4: Survival by volume

Considering that higher KPS scores have commonly been reported as a predictor of favorable prognosis, we analyzed survival based on lesion number, volume, age and gender stratified by KPS $>70$ and $\leqslant 70$. In patients with KPS $>70$, those with more than three lesions had a median survival of 6.25 months ( $95 \% \mathrm{Cl}: 4.41-7.83$ ), while those with fewer lesions survived for a median of 9.77 months ( $95 \% \mathrm{Cl}: 7.76$ - 11.35), $\mathrm{p}<0.0001$. Similarly, patients older than 65 years had a significantly worse survival (median survival: $6.48,95 \% \mathrm{Cl}: 4.74-9.18$ months) than those younger than 65 years (median survival-8.52 months, $95 \% \mathrm{Cl}: 7.14-10.63$ months) $\mathrm{p}=0.03$. Smaller volume $(<8.4)$ was similarly found to be associated with better survival (median survival: 9.64 months versus 6.58 months, $\mathrm{p}=0.003$ ). No other covariate variables, including gender, histology (adenocarcinoma versus others), and time to metastasis from the time of diagnosis of primary cancer, were found to be significant.

When the subgroup of patients with KPS of 70 or lower were analyzed, no significant difference in survival was found when stratified by number of lesions, the volume of lesions, age, gender, or histology. However, patients who were diagnosed with brain metastases within two months of diagnosis of primary carcinoma survived for significantly less time with a median of only 2.50 months (95\% Cl: 1.84-5.69 months) (Figures 5, 6). 


\section{Cureus}

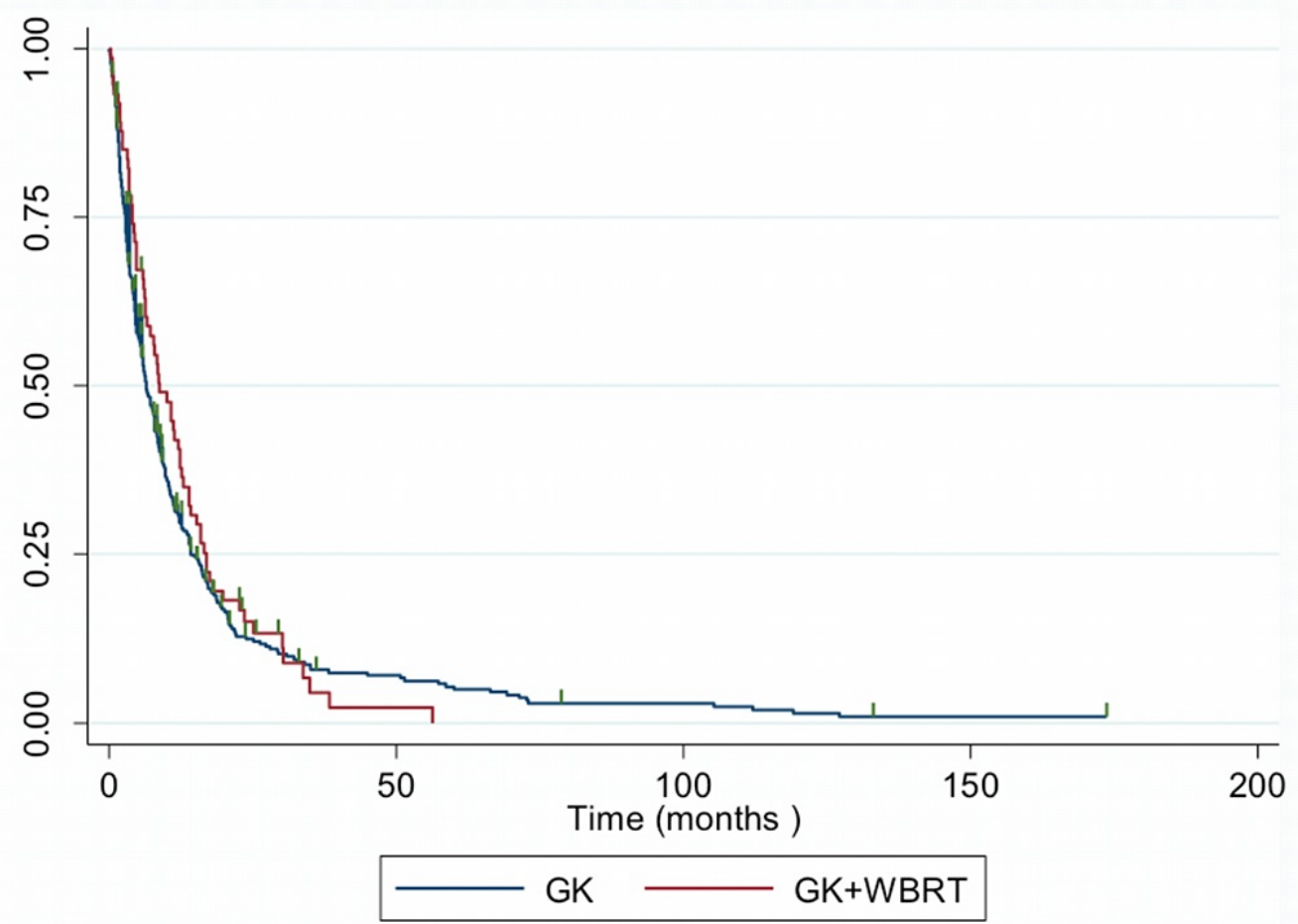

FIGURE 5: Survival by adjuvant whole brain radiation

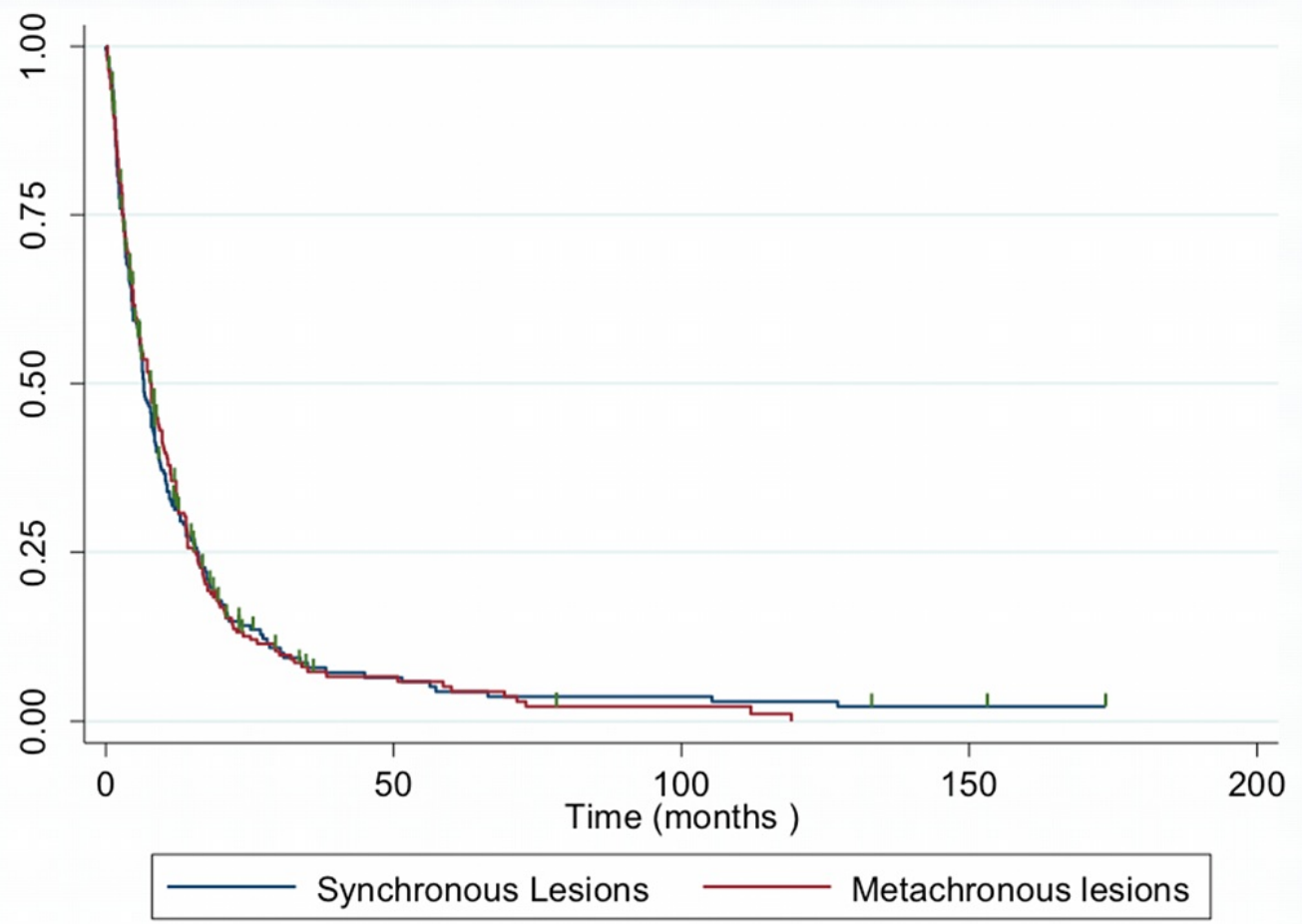

FIGURE 6: Survival of synchronous versus metachronous lesions 
Patients who developed delayed cerebral metastasis survived for a median of 6.09 months (95\% $\mathrm{Cl}$ : 3.42-13.59 months), $\mathrm{p}=0.006$. A multivariate analysis revealed KPS scores, age, number of lesions, and dose to be associated with risk of mortality. Patients aged older than 65 years were 1.43 times more likely to die than those younger (Odds ratio: $1.43,95 \% \mathrm{Cl}: 1.16-1.77, \mathrm{p}<0.001$ ). Similarly, presence of more than three lesions was associated with a risk of mortality 1.51 times higher than those who had three or fewer lesions (Odds ratio: 1.51 95\% $\mathrm{Cl}: 1.20-1.89, \mathrm{p}<$ 0.0001). Patients with KPS score of 70 or less were 1.54 times more likely to die than those with a KPS score of 80 or greater (1.54 95\% CI: 1.21-1.97, p < 0.001). When the dose was incorporated as a continuous variable, a higher dose was significantly associated with better survival. We, therefore, dichotomized dose delivered to patients at $18 \mathrm{~Gy}$ to assess the risk of mortality at lower doses when compared to higher. A dose less than $18 \mathrm{~Gy}$ was associated with a 1.36 times greater risk of mortality than those irradiated with a higher dose (Odds ratio: $1.36,95 \% \mathrm{CI}$ : $1.09-1.70, \mathrm{p}=0.007$ ). While volume $\leqslant 8.4$ (median volume) was found to be significant on univariate analysis (Table 3) (Figure 6), it was not a significant prognostic factor in multivariate analysis. A subgroup analysis of patients with KPS scores 70 or lower demonstrated synchronicity of diagnosis of brain with that of primary cancer (defined as within two months of each other) as the only significant predictor of mortality (hazard ratio $=1.89,95 \% \mathrm{Cl}: 1.18$ 3.03). In multivariate analysis of patients with KPS $>70$, factors associated with favorable prognosis were similar to those found when including the entire study population (Figure 7). Age greater than 65 (hazard ratio $=1.48,95 \% \mathrm{Cl}: 1.16-1.90, \mathrm{p}=0.002$ ), two to three lesions (hazard ratio $=1.39,95 \% \mathrm{Cl}: 1.03-1.89, \mathrm{p}=0.038$ ), lesions $>3$ (hazard ratio $=2.05,95 \% \mathrm{Cl}: 1.52-$ 2.76, $\mathrm{p}<0.001$ ), and dose $<18 \mathrm{~Gy}$ (hazard ratio $=1.33,95 \% \mathrm{Cl}: 1.02-1.72, \mathrm{p}=0.032$ ) were found to be independent predictors of improved survival.

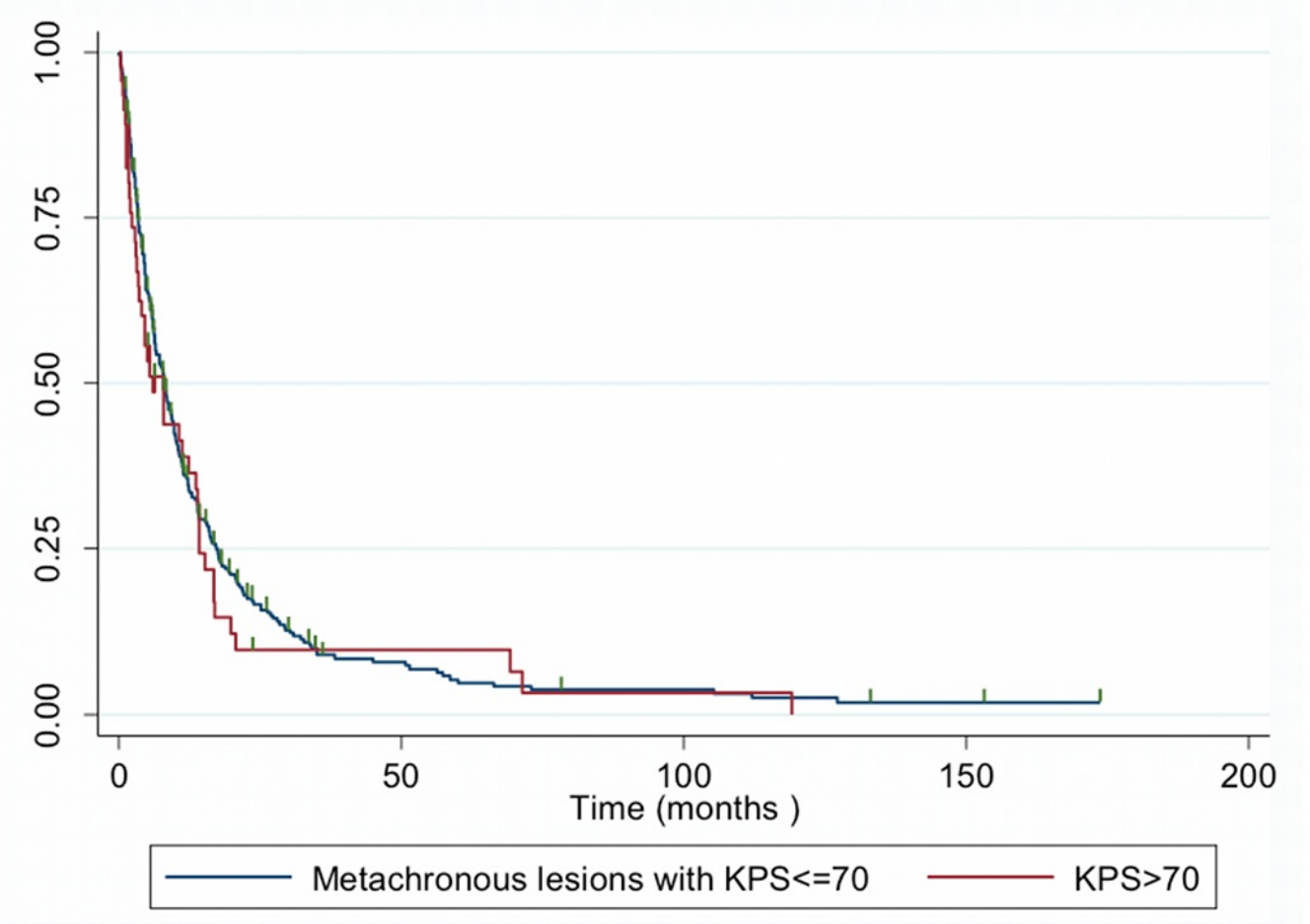

FIGURE 7: Survival metachronous lesions in patients with KPS $<70$ versus $\mathrm{KPS}>70$

\section{Progression free survival (PFS)}


The overall duration of median PFS was 3.98 months (95\% Cl 3.49-4.67 months) with 441 (94.24\%) patients dying or progressing out of 468 patients over the follow-up period. KaplanMeier analysis revealed KPS $>70$, lesions $<3$, and volume $<8.4 \mathrm{ml}$ were associated with higher PFS than the complementary variables. No significant difference in PFS was revealed upon stratification by age (age $>65$ versus age $<65$ ), gender, or histology (adenocarcinoma versus others).

\section{Discussion}

Non-small cell lung carcinoma is one of the most common tumors to metastasize to brain [1314] resulting in mortality within one to two months when untreated [15]. Several reports have demonstrated improvement in survival after radiosurgery to a median survival of seven to 11 months [16-20]. Many of these studies are limited because outcomes are confounded by the inclusion of multiple primary pathologies, each behaving differently. This study reports outcomes of 469 patients with one primary pathology, NSCLC, treated at two tertiary care institutions. Our median survival following radiosurgery was 7.14 months which concurs with most reports [16-20]. We found that KPS scores, the multiplicity of intracranial lesions and age as independent determinants of mortality in metastatic NSCLC after treatment with radiosurgery.

The survival was analyzed based on Karnofsky performance status, with patients with higher scores surviving longer. Median survival for patients with performance status higher than 70 was 7.93 months while for patients with 70 or lower KPS it was 4.34 months. This association of performance status with better survival has been shown across different primary tumors, including NSCLC [14, 17, 21]. The performance status was a significant predictor of mortality in both univariate and multivariate analysis. Our subgroup analysis revealed a significant interaction of performance status with other variables. On multivariate analysis stratified for KPS $<70$, only synchronicity of metastasis (progression of primary NSCLC lesions to intracranial metastasis within two months) yielded a statistically significant decrease in survival. Importantly, in patients with KPS > 70 synchronous metastasis did not significantly alter mortality rates. Similar to our results, a series of NSCLC metastases reported by Flannery, et al. revealed synchronicity of brain metastasis with the primary lesion to be a significant factor in determining the risk of mortality. However, this effect was found across the series, irrespective of KPS scores [22]. It is noteworthy that these results were reported in patients with solitary metastasis which may limit the comparison of those results with this series. However, in another report, Sheehan, et al. reported on multivariate analysis of their series a greater risk of mortality with synchronous than with metachronous lesions, but the number of metastases did not alter mortality rates [23]. In our series, patients with KPS $<70$ with synchronous lesions had a survival of 2.5 months as compared to 6.09 months in patients with metachronous lesions. Also, in patients with KPS $<70$ and metachronous lesions, survival (mortality: 91.30\% and median survival: 6.09 months) was similar to that in patients with KPS > 70 (mortality: $87.53 \%$ and median survival: 7.89 months) $(\mathrm{p}=0.3)$. Furthermore, both univariate and multivariate analysis in this subgroup of patients revealed that higher KPS was not a significant predictor of mortality when adjusted for age, number of lesions, gender, and volume (univariate odds ratio $0.86,95 \% \mathrm{Cl}: 0.62-1.19, \mathrm{p}=0.364$ ). These results suggest that in patients with delayed progression of primary lesions to brain metastasis, survival may not be determined by KPS scores alone. Other factors which may to a greater extent influence survival than KPS are extracranial control and extracranial causes of low KPS [9, 11]. Lutterbach, et al. analyzed a subgroup of 408 patients with KPS $<70$ and reported that age $<65$, solitary intracranial lesions, and control of primary disease were independent predictors of survival [9]. Chernov, et al. identified differences between survival of patients with extracranial causes of poor KPS versus intracranial. Patients with low KPS secondary to intracranial lesions had a median survival of six months, whereas in patients with both intracranial and extracranial progression causing poor KPS had a median survival of 3.3 months. Moreover, poor KPS when 
caused by only extracranial disease, had a median survival of one month. Although our results were not adjusted for these possible confounders, this study, along with other series described above, suggest that a subclass of patients with low KPS/RPA III should be treated aggressively with a goal to control both extracranial and intracranial disease instead of common practice of palliation of patients in RPA III. Furthermore, in patients with synchronous disease where survival is associated with control of both intracranial and extracranial disease [24], the decision to treat brain metastasis may be guided by the ability to control the primary tumor.

The predictors of survival in patients with KPS scores higher that 70 were different from patients with KPS $<70$. Multiple metastasis $(>3)$ and age greater than 65 were the clinical features found to be significantly associated with poor outcomes for univariate and multivariate analysis in patients with KPS $>70$. Unlike patients with poorer KPS, the synchronicity of brain metastasis was not associated with worse outcomes in patients with KPS $>70$.

Median survival was 7.86 months (95\% CI: 6.22-9.77 months) in patients with three or fewer lesions which was significantly higher than the patients with greater than three lesions (5.99 months 95\% CI: 4.41-7.66 months), with a log-rank value of $\mathrm{p}=0.0001$. In agreement with our results, other series have also reported higher survival with solitary metastasis and poor outcomes with multiple lesions $[4,9,16]$. Di Luna, et al. reported that in 336 patients with metastatic tumors (36\% NSCLC), patients with greater than four lesions had a median survival of 6.1 months, while patients with patients with fewer lesions survived for a median of nine months. In that report, 113 patients harboring metastatic NSCLC had a median survival of 12.9 months, 12.0 months, 13.1 months and eight months (since radiosurgery) when there were solitary, two lesions, three lesions and greater than three lesions, respectively. Though the trend is consistent with our results, their study shows overall higher survival rates that may be attributed to $93 \%$ of their patients having KPS of 70 or higher and $68 \%$ being younger than 65 years. Flannery, et al., in their series, reported a median survival of 33 months versus 8.6 months in metachronous versus synchronous metastasis [22]. These results are in agreement with our results of higher survival for patients with solitary metachronous lesions.

A major limitation of the study is lack of detailed data regarding extracranial disease. We were, however, able to observe a lower neurological mortality rate in metastases of NSCLC (8.5\%) than observed in our entire brain metastases experience consisting of all histologies (12.30\%).This suggests that brain metastases from NSCLC may be more sensitive to SRS than other histologies.

\section{Conclusions}

Stereotactic radiosurgery provides an efficacious treatment option for patients with NSCLC metastatic to the brain in patients with fewer lesions ( $<3$ lesions), younger age $(<65$ years) and higher KPS scores $(>70)$. SRS may also be effective in prolonging survival in patients with metachronous lesions despite low KPS scores.

\section{Additional Information}

\section{Disclosures}

Human subjects: Consent was obtained by all participants in this study. The Johns Hopkins Institutional Review Board issued approval N/A. Animal subjects: All authors have confirmed that this study did not involve animal subjects or tissue. Conflicts of interest: In compliance with the ICMJE uniform disclosure form, all authors declare the following: Payment/services info: All authors have declared that no financial support was received from any organization for the submitted work. Financial relationships: We declare(s) a grant from Elekta AB. Education grant. Other relationships: All authors have declared that there are no other 
relationships or activities that could appear to have influenced the submitted work.

\section{References}

1. Hazra T, Mullins GM, Lott S: Management of cerebral metastasis from bronchogenic carcinoma. Johns Hopkins Med J. 1972, 130:377-383.

2. Gaspar L, Scott C, Rotman M, et al: Recursive partitioning analysis (RPA) of prognostic factors in three Radiation Therapy Oncology Group (RTOG) brain metastases trials. Int J Radiat Oncol Biol Phys. 1997, 37:745-751. 10.1016/S0360-3016(96)00619-0

3. Abrahams JM, Torchia M, Putt M, et al: Risk factors affecting survival after brain metastases from non-small cell lung carcinoma: a follow-up study of 70 patients. J Neurosurg. 2001, 95:595-600. 10.3171/jns.2001.95.4.0595

4. Zabel A, Milker-Zabel S, Thilmann C, et al: Treatment of brain metastases in patients with non- small cell lung cancer (NSCLC) by stereotactic linac-based radiosurgery: prognostic factors. Lung Cancer. 2002, 37:87-94. 10.1016/S0169-5002(02)00030-2

5. Flannery TW, Suntharalingam M, Kwok Y, et al: Gamma Knife stereotactic radiosurgery for synchronous versus metachronous solitary brain metastases from non-small cell lung cancer. Lung Cancer. 2003, 42:327-333. 10.1016/S0169-5002(03)00357-X

6. Frazier JL, Batra S, Kapor S, et al: Stereotactic radiosurgery in the management of brain metastases: an institutional retrospective analysis of survival. Int J Radiat Oncol Biol Phys. 2010, 76:1486-1492. 10.1016/j.ijrobp.2009.03.028

7. Lorenzoni J, Devriendt D, Massager N, et al: Radiosurgery for treatment of brain metastases: estimation of patient eligibility using three stratification systems. Int J Radiat Oncol Biol Phys. 2004, 60:218-224. 10.1016/j.ijrobp.2004.02.017

8. Gaspar LE, Scott C, Murray K, et al: Validation of the RTOG recursive partitioning analysis (RPA) classification for brain metastases. Int J Radiat Oncol Biol Phys. 2000, 47:1001-1006. 10.1016/S0360-3016(00)00547-2

9. Lutterbach J, Bartelt S, Stancu E, et al: Patients with brain metastases: hope for recursive partitioning analysis (RPA) class 3. Radiother Oncol. 2002, 63:339-345. 10.1016/S01678140(02)00119-6

10. Buchsbaum J, Suh J, Lee S, et al: Survival by radiation therapy oncology group recursive partitioning analysis class and treatment modality in patients with brain metastases from malignant melanoma: a retrospective study. Cancer. 2002, 94:2265-2272. 10.1002/cncr.10426

11. Chernov M, Nakaya K, Izawa M, et al: Outcome after radiosurgery for brain metastases in patients with low Karnofsky performance scale (KPS) scores. Int J Radiat Oncol Biol Phys. 2007, 67:1492-1498. 10.1016/j.ijrobp.2006.11.023

12. Weltman E, Salvajoli J, Brandt R, et al: Radiosurgery for brain metastases: who may not benefit?. Int J Radiat Oncol Biol Phys. 2001, 51:1320-1327. 10.1016/S0360-3016(01)01696-0

13. Nussbaum E, Djalilian H, Cho K, et al: Brain metastases. Histology, multiplicity, surgery, and survival. Cancer. 1996, 78:1781-1788. 10.1002/(SICI)1097-0142(19961015)78:8<1781::AIDCNCR19>3.0.CO;2-U

14. Karlsson B, Hanssens P, Wolff R, et al: Thirty years' experience with Gamma Knife surgery for metastases to the brain. J Neurosurg. 2009, 111:449-457. 10.3171/2008.10.JNS08214

15. Hazra T, Mullins G, Lott S: Management of cerebral metastasis from bronchogenic carcinoma . Johns Hopkins Med J. 1972, 130:377-383.

16. Hoffman R, Sneed P. McDermott M, et al: Radiosurgery for brain metastases from primary lung carcinoma. Cancer J. 2001, 7:121-131.

17. Sperduto P. Chao S, Sneed P. et al: Diagnosis-Specific Prognostic Factors, Indexes, and Treatment Outcomes for Patients with Newly Diagnosed Brain Metastases: A MultiInstitutional Analysis of 4,259 Patients. Int J Radiat Oncol Biol Phys. 2009, 77:655-61. 10.1016/j.ijrobp.2009.08.025

18. Flickinger J, Kondziolka D, Lunsford L, et al: A multi-institutional experience with stereotactic radiosurgery for solitary brain metastasis. Int J Radiat Oncol Biol Phys. 1994, 28:797-802. 10.1016/0360-3016(94)90098-1

19. Kano H, Kondziolka D, Zorro 0, et al: The results of resection after stereotactic radiosurgery for brain metastases. J Neurosurg. 2009, 111:825-831. 10.3171/2009.4.JNS09246

20. Chen J, Petrovich Z, O'Day S, et al: Stereotactic radiosurgery in the treatment of metastatic disease to the brain. Neurosurg. 2000, 47:268-279. 10.1097/00006123-200008000-00003 


\section{Cureus}

21. Lagerwaard F, Levendag $P$, Nowak $P$, et al: Identification of prognostic factors in patients with brain metastases: a review of 1292 patients. Int J Radiat Oncol Biol Phys. 1999, 43:795-803. 10.1016/S0360-3016(98)00442-8

22. Flannery T, Suntharalingam M, Kwok Y, et al: Gamma knife stereotactic radiosurgery for synchronous versus metachronous solitary brain metastases from non-small cell lung cancer. Lung Cancer. 2003, 42:327-333. 10.1016/S0169-5002(03)00357-X

23. Sheehan J, Sun M, Kondziolka D, et al: Radiosurgery for non-small cell lung carcinoma metastatic to the brain: long-term outcomes and prognostic factors influencing patient survival time and local tumor control. J Neurosurg. 2002, 97:1276-1281.

10.3171/jns.2002.97.6.1276

24. Kong D, Lee J, Nam D, et al: Prognosis of non-small cell lung cancer with synchronous brain metastases treated with Gamma Knife radiosurgery. J Korean Med Sci. 2006, 21:527-532.

10.3346/jkms.2006.21.3.527 